\title{
A Community and Technology-Based Approach for Hypertension Self-Management (COACHMAN) to Improve Blood Pressure Control in African Americans: Results from a Pilot Study
}

This article was published in the following Dove Press journal:

Patient Preference and Adherence

\author{
Carolyn H Still $\mathbb{D}^{\prime}$ \\ Seunghee Margevicius ${ }^{2}$ \\ Carla Harwell ${ }^{3,4}$ \\ Ming-Chun Huang ${ }^{5}$ \\ LaTonya Martin (iD) ${ }^{6}$ \\ Phuong B Dang' \\ Jackson T Wright Jnr $\mathrm{r}^{3,7}$ \\ 'Frances Payne Bolton School of Nursing, \\ Case Western Reserve University, \\ Cleveland, OH, USA; ${ }^{2}$ Department of \\ Population and Quantitative Health \\ Sciences, School of Medicine, Case \\ Western Reserve University, Cleveland, \\ $\mathrm{OH}, \mathrm{USA} ;{ }^{3}$ Department of Internal \\ Medicine, School of Medicine, Case \\ Western Reserve University, Cleveland, \\ $\mathrm{OH}$, USA; ${ }^{4}$ University Hospitals \\ Cleveland Medical Center, Cleveland, \\ OH, USA; ${ }^{5}$ Department of Electrical \\ Engineering and Computer Science, Case \\ School of Engineering, Case Western \\ Reserve University, Cleveland, OH, USA; \\ ${ }^{6}$ Community Partners, Cleveland Council \\ of Black Nurses, Cleveland, OH, USA; \\ ${ }^{7}$ Department of Nephrology and \\ Hypertension, Clinical Hypertension \\ Program, University Hospitals Cleveland \\ Medical Center, Cleveland, $\mathrm{OH}$, USA
}

Correspondence: Carolyn H Still Frances Payne Bolton School of Nursing, Case Western Reserve University, 10900 Euclid Ave, Cleveland, OH 44106, USA

Tel + I 2163686338

Fax +I 2163683452

Email cwhl I@case.edu
Purpose: Adoption of technology has increased to support self-managing chronic diseases. However, behavioral interventions evaluating such technology have been understudied in African Americans with hypertension. The aim of this study was to explore a community and technology-based intervention for hypertension self-management (COACHMAN) intervention on blood pressure (BP) control and health-related quality of life (HRQoL) in African Americans with hypertension.

Methods: Sixty African Americans (mean age 60; 75\% females) who were prescribed antihypertensive medications and owning a smartphone were randomized to the COACHMAN ( $\mathrm{n}=$ $30)$ or enhanced usual care $(n=30)$ group for 12 weeks. COACHMAN is comprised of four components: web-based education, home BP monitoring, medication management application, and nurse counseling. Hypertension knowledge, self-efficacy, technology adoption/use, medication adherence, BP, and HRQoL scores were assessed.

Results: Mean systolic and diastolic BP at baseline was $150.49(\mathrm{SD}=13.89)$ and $86.80(\mathrm{SD}=$ 13.39), respectively. After completing the 3-month intervention to improve hypertension selfmanagement, the groups did not significantly differ in BP control and HRQoL. Clinically relevant BP reduction was observed in the intervention group. Paired $t$-test showed that mean medication-taking adherence scores significantly improved in the intervention group $(P=0.023)$ compared to the control group $(P=0.075)$.

Conclusion: Using technology may have a positive impact on supporting hypertension selfmanagement, particularly in medication-taking adherence. Further research is warranted in a larger sample and should include standardization of medication management to isolate the effects of behavioral interventions on changes in BP.

Clinicaltrials.gov Identifier: NCT03722667.

Keywords: African Americans, hypertension, minority health, technology, self-management

\section{Introduction}

Hypertension is the most common, modifiable risk factor for cardiovascular disease, with nearly one in two US adults aged 20 years and older (108 million) estimated to suffer from this condition. ${ }^{1,2}$ As the current US hypertension guideline now recommends a blood pressure (BP) target of less than $130 / 80 \mathrm{mmHg},{ }^{1,3}$ more adults are faced with the challenge of managing this chronic disease. Rates of hypertension are disproportionately observed in non-Hispanic African Americans 
(54\%) when compared to non-Hispanic Whites (46\%), Asian adults $(39 \%)$, or Hispanic adults $(36 \%))^{1,2}$ More alarming is that less than half of US adults have their hypertension under control (48.3\%), and these rates are lower among African Americans. Research has welldocumented the negative effects of poorly controlled BP on well-being and health outcomes. ${ }^{4-6}$ In addition, uncontrolled BP is a primary and contributing cause of concomitant morbidity and increase mortality rates, ${ }^{4,5}$ and has been estimated to cost the healthcare system $\$ 131$ billion each year. ${ }^{2,4}$

Self-managing hypertension requires individuals to engage in lifestyle behavioral changes including eating a balanced diet, performing regular physical activity, selfmonitoring BP, and most important, adhering to antihypertensive medication. ${ }^{1}$ However, effectively controlling BP remains a challenge and growing concern, despite advances in pharmacotherapy for hypertension. ${ }^{6}$ Suboptimal adherence to medication-taking occurs in $43-78 \%$ of patients prescribed antihypertensive therapy, ${ }^{7}$ with $50 \%$ discontinuing their medications after 1 year, ${ }^{8}$ and notably, a trend more prevalent in African Americans. ${ }^{9}$ Strong evidence suggests that suboptimal/ poor adherence to antihypertensive therapy is multifactorial and associated with socioeconomic factors, the healthcare system/team (provider-patient interaction), prescribed treatment regimen (dose, frequency, drug efficacy, side effects), and patient factors (low self-efficacy, social support). ${ }^{3,6,7,10}$ Furthermore, uncontrolled hypertension is associated with the disproportionately high burden and progressively worse health outcomes of stroke, heart disease, end-stage renal disease, and quality of life in African Americans with hypertension. ${ }^{4,11}$

\section{Hypertension Self-Management with Technology}

Previous behavioral interventions have attempted to improve hypertension outcomes by implementing educational interventions targeted at increasing ones' knowledge about hypertension to influence positive health behavioral change. ${ }^{12}$ Owing to the fact that educational interventions do not translate to large BP reductions, greater efforts are needed to support self-managing hypertension, including medication-taking adherence, especially in African Americans. ${ }^{13}$ Over the last decade, the rapid development and adoption of technology such as mHealth tools (e.g. smartphones, mobile applications [apps]), patient monitoring devices, and other wireless devices have increased to support self-managing chronic disease, ${ }^{14-17}$ including cardiovascular disease (CVD). ${ }^{18-21}$ Data has also shown there has been an uptake in technology use among African Americans in terms of technology ownership (smartphones, tablets, laptops), as well as their increased access to the internet. ${ }^{22,23}$ However, comprehensive reviews have demonstrated that African Americans are underrepresented in technology research to improve health. ${ }^{14,24,25}$ Among those studies that have investigated technology and mHealth for improving hypertension self-management, the results are inconsistent, primarily conducted outside of the US, often lacking a theoretical framework, and limited in their generalizability to diverse populations. ${ }^{14,26}$ Given that the current evidence is sparse for the efficacy of mHealth and technology-supported behavioral health interventions in African American adults with hypertension, ${ }^{24}$ efforts are needed to develop behavioral interventions that incorporate technology to support and sustain self-managing hypertension. ${ }^{6,22,23}$

Based on the identified gaps in the literature, our study is guided by the Ryan and Swain's Individual and Family Self-Management Theory (IFSMT) ${ }^{27}$ to offer a systematic approach and scientific basis for studying the factors and relationships that contribute to self-managing a chronic disease such as hypertension in African Americans using technology. The IFSMT suggests that self-management takes place through a process, where patient-centered interventions are directed at increasing knowledge and skills, as well as self-regulation skills and abilities, while taking into account the presence of contextual factors specific to the individual, their health condition, and their physical and social environment. It is through the selfmanagement process that individuals improve their health behaviors and, in turn, achieved positive health outcomes and quality of life. ${ }^{27}$ The IFSMT has been tested for effectiveness and applied to a variety of chronic health conditions across diverse populations. ${ }^{28,29}$ Therefore, we use the IFSMT as a framework to engage African Americans with hypertension in health-promoting behaviors using a technology-based intervention to support self-managing hypertension to improve BP and healthrelated quality of life (HRQoL). ${ }^{25}$

Furthermore, we used the principles of communitybased participatory research (CBPR) to design and conduct this study in two phases (the design and planning phase and the implementation phase) with community- 
provider partnerships that included the local Center for Reducing Health Disparities, the American Heart Association, and the Cleveland Council of Black Nurses $(\mathrm{CCBN})$. Herein, we report the findings of the implementation phase. Therefore, the purpose of this study was to test the effectiveness of a technology-based intervention in improving BP control and HRQoL in African Americans with hypertension. Our primary hypothesis for this study was that individuals assigned to the intervention group would have better BP control and improved HRQoL, a subsequent result from improving their adherence to antihypertensive medication-taking compared to those individuals assigned to the EUC control group.

\section{Materials and Methods Study Design}

The COACHMAN Study (A COmmunity and Tech-Based ApproaCh for Hypertension Self-MANagement) is a CBPR study utilizing a pilot randomized controlled trial design. ${ }^{25}$ This research protocol was approved by the University Hospitals Cleveland Medical Center's (UHCMC) Institutional Review Board. All study participants provided written informed consent prior to study enrollment.

\section{Study Setting and Participants}

Participants were recruited from the hospital and affiliated community clinics at UHCMC, as well as from community outreach and engagements using various recruitment methods. ${ }^{30-32}$ Participants were eligible for this study if they (1) self-identified as African American, (2) were 30 years of age or older, (3) had been diagnosed with hypertension (BP >140/90 $\mathrm{mmHg}$ ) and prescribed an antihypertensive drug, (4) were able to read/understand English, and (5) owned a smartphone. Individuals were excluded if they had a history of cognitive impairment or recent hospitalization or emergency department visit related to hypertension. We screen 109 potential participants via phone to determine initial eligibility. Sixty participants meeting the inclusion criteria completed the screening visit and were enrolled. Given that this is a preliminary pilot trial, the sample size was conservatively selected to establish an appropriate sample size for a planned larger clinical trial. ${ }^{33}$

\section{Procedures}

Participants who met study requirements were invited to schedule a screening visit to further determine their eligibility, provide informed consent, and obtain an initial BP. Eligible participants were scheduled within 7 days for baseline visits with a trained research assistant (RA). At the baseline visit, data were collected on anthropometric measurements (height, weight, body mass index [BMI]), BP, and blood chemistries. After participants completed a series of study questionnaires, they were randomly assigned using a computer-number generator for a 1:1 allocation to the intervention or control group. Participants randomized to the intervention receive oneon-one training on how to use the technology-based components of the intervention. Details about the study conditions are described below. Data were collected at baseline, 8 weeks, and 12 weeks and each visit took approximately 1.5 hours to complete. The COACHMAN study rationale and design has been previously reported. ${ }^{25}$

\section{Intervention Group}

The COACHMAN intervention is a 12-week intervention that consisted of three technology components and nurse counseling (Table 1) to support self-managing hypertension in African Americans. ${ }^{25}$ The first component, webbased education modules, focused on improving one's knowledge, skills, and attitudes about hypertension management based on the literature and recommendations and resources from the local American Heart Association, the Centers for Disease Control and Prevention, and community partners. ${ }^{25}$ Each education module was approximately 7-10 minutes in duration and was delivered weekly for 6 weeks, accessible on a standard web browser compatible with an average household or library computer or mobile device.

The second component consisted of self-monitoring BP with a study provided, automatic home BP device (Omron Series 10). Participants received instructions and training on how to self-monitor their BP, and were asked to monitor their BP twice a day (morning and evening), on two nonconsecutive days each week over a 3-month period, and then record their BP measurements on the study's tracking log. The tracking logs were verified by the research assistant at each visit with data stored on the study provided home BP monitor.

The third component consisted of using a commercially free medication management app, Medisafe (www.Medisafe.com). This app operates on Android and iOS phone systems, and provides personalized medication adherence support. For example, key features of Medisafe include its ability to provide SMS 
Table I COACHMAN Intervention Components

\begin{tabular}{|c|c|c|c|}
\hline Intervention Component & Duration & \multicolumn{2}{|c|}{ Content } \\
\hline \multirow[t]{2}{*}{$\begin{array}{l}\text { I. Web-based hypertension } \\
\text { education }\end{array}$} & \multirow[t]{2}{*}{$\begin{array}{l}\text { Six weekly module, }<10 \text { minutes in } \\
\text { duration }\end{array}$} & \multicolumn{2}{|c|}{$\begin{array}{l}\text { Delivers knowledge about hypertension, including managing the } \\
\text { disease, monitoring blood pressure, medication adherence via } \\
\text { a web-based module }\end{array}$} \\
\hline & & $\begin{array}{l}\text { Week } 1 \\
\text { Week } 2 \\
\text { Week } 3 \\
\text { Week } 4 \\
\text { Week } 5 \\
\text { Week } 6\end{array}$ & $\begin{array}{l}\text { Overview and understanding hypertension } \\
\text { Self-monitoring your blood pressure } \\
\text { Importance of adherence to your blood pressure } \\
\text { medications } \\
\text { Modifying behaviors-Increasing physical activity } \\
\text { Modifying behaviors-Healthy diet } \\
\text { Understanding health consequences of hypertension }\end{array}$ \\
\hline $\begin{array}{l}\text { 2. Self-monitoring blood pressure } \\
\text { (BP) }\end{array}$ & 12 weeks & \multicolumn{2}{|c|}{$\begin{array}{l}\text { Participants instructed to monitor and record blood pressure two } \\
\text { non-consecutive days/week, twice a day, for a total of } 12 \text { weeks } \\
\text { with an Omron } 10 \text { Series home BP monitor, provided by study. }\end{array}$} \\
\hline $\begin{array}{l}\text { 3. Medication management } \\
\text { support }\end{array}$ & 12 weeks & \multicolumn{2}{|c|}{$\begin{array}{l}\text { I. Participants were instructed and trained to use the Medisafe } \\
\text { medication management application on their smartphone to } \\
\text { support medication adherence. } \\
\text { 2. Participants were provided daily medication reminders and } \\
\text { updates about their antihypertensive medication over the } 12 \text { - } \\
\text { week study period. }\end{array}$} \\
\hline 4. Nurse counseling sessions & 30 minutes phone sessions & \multicolumn{2}{|c|}{$\begin{array}{l}\text { Participants received up to four counseling sessions with } \\
\text { a research nurse to support self-managing hypertension over } 12 \\
\text { weeks. }\end{array}$} \\
\hline
\end{tabular}

reminder messages/alerts of when to take medication, generate weekly adherence reports, input and monitor biometric data (e.g. BP and glucose), and provide updates on selected health information, medications, and lifestyle tips. During the baseline visit, study participants received support from the research assistant with downloading the Medisafe app, followed by a 20 -minute training session on how to use the app, including adding information on each prescribed antihypertensive medication to the app. Study participants were asked to use the app for 12 weeks for medication-taking adherence support.

The fourth component consisted of nurse counseling sessions with registered nurses from the CCBN (community partner and local chapter of the National Black Nurses Association). Similar to community health workers, CCBN nurses serve as a bridge between underserved communities and their healthcare needs, and engaged the study participants by delivering heart health education and skillbuilding strategies to improve their HRQoL. ${ }^{34-, 37}$ Guided by culturally appropriate educational materials in "On the Move to Better Heart Health for African Americans" (developed by the National Institutes of Health, National
Heart, Lung, and Blood Institute), the nurses provided 3-4 sessions of informal counseling focused on discussing medication adherence and BP monitoring BP, and other topics guided by the participant.

\section{Control Group}

In addition to standard care, the EUC control group received printed educational materials on managing hypertension and access to one web-based education session on self-monitoring BP. Study participants were also given a home BP monitor (Omron 10 Series) and trained by the research assistant to properly use the device. However, participants in the control group were not required to monitor their $\mathrm{BP}$.

\section{Measures}

\section{Demographic and Hypertension Characteristics}

Data on demographic and hypertension characteristics were assessed at baseline. Demographics included age, gender, income, education, and marital status, while hypertension-related characteristics included years diagnosed 
with hypertension, history of smoking, comorbidities, and number and type of antihypertensive medications. In addition, we collected clinical data pertinent to CVD risk and relevant to hypertension management, such body mass index (BMI), and high-density lipoprotein (HDL) and lowdensity lipoprotein (LDL) cholesterol at baseline and 12 weeks.

\section{Blood Pressure Change}

At each clinic visit (baseline, 8 weeks, and 12 weeks), BP was measured by trained staff at the UHCMC Dahms Clinical Research Unit with an automated device (Omron HEM-907XL, Omron Healthcare, Inc., Bannockburn, IL) that was calibrated according to manufacturer's specifications. Using standardized procedures, ${ }^{38}$ including the appropriately sized cuff and technique, BP readings were taken after a 5-minute rest, ${ }^{1}$ and the average of three BP readings was recorded at each visit. As noted, our primary outcome was change in BP from baseline to 12 weeks, in which the 12 weeks mean systolic/diastolic BP minus the baseline mean systolic/diastolic BP was calculated for a mean change score. A secondary goal of this study was to achieve lower BP targets (BP $<130 / 80 \mathrm{mmHg}$ ) as recommended by the American College of Cardiology/ American Heart Association (ACC/AHA) 2017 hypertension guideline in at least $65 \%$ of those individuals assigned to the intervention group. ${ }^{1}$

\section{Health-Related Quality of Life}

HRQoL, another primary outcome for this study, was measured using the Patient-Reported Outcomes Measurement Information System (PROMIS) Global-10 at baseline and 12 weeks. ${ }^{39}$ The PROMIS Global-10 is a 10-item questionnaire that assesses the general quality of life (QOL) divided into two domains-physical and mental health. Each domain's scores are derived using T-score normal population distribution mean \pm standard deviation (SD) of $50 \pm 10$, where higher scores indicate better health. ${ }^{40}$ The PROMIS Global-10 has been tested in diverse populations with various chronic diseases and is a valid and reliable measure $(\alpha=0.82){ }^{40}$

\section{Medication Adherence}

The performance and self-report of adherence to hypertension treatment was measured with the Hill-Bone Compliance to High Blood Pressure Therapy Scale. ${ }^{41}$ The Hill-Bone Scale consists of 14 items on a 4-point Likert-type scale that assesses three domains of hypertension management (mediation-taking, diet, appointment keeping). In this study, we examined the medication-taking subscale scores, which consisted of nine items on a 4-point Likert-type scale (responses range 1 to 4 ) with lower scores indicating better medication-taking adherence behaviors $(\alpha=0.71$ and 0.75$) .{ }^{41,42}$ Additionally, we examined adherence to medication-taking of individuals assigned to the intervention group with the Medisafe app, where individuals responded (skipped, snoozed, or taken) to medication reminders for prescribed antihypertensives. We further classified responses based on adherence reports provided by Medisafe as non-responders $(<80 \%$ use) or responders ( $>80 \%$ use).

\section{Self-Management Process}

To examine the self-management process, we assessed hypertension knowledge and awareness using the Hypertension Knowledge-Level Scale (HK-LS). ${ }^{43}$ The HK-LS is a 22-item interval scale that measures six domains (medical treatment, drug compliance, lifestyle, diet, and complications) of hypertension, and has good reliability $(\alpha=0.82){ }^{43}$ Total possible points on the HKLS is 22, with higher scores indicating higher levels of hypertension knowledge. Another component of the selfmanagement process assessed in this study was selfefficacy, measured on the Self-Efficacy for Managing Chronic Disease Scale. ${ }^{44}$ This is a 6-item rating scale used to assess one's confidence in performing activities to self-manage a chronic condition and has been validated in various chronic diseases, including hypertensive patients $(\alpha=0.91){ }^{44}$ Scores ranged from 1 to 10 , with higher scores indicating greater self-efficacy to manage a chronic disease. ${ }^{44}$ Lastly, we assessed the process of engaging with and the adoption of technology using two valid and reliable measures, the System Usability Scale (SUS; $\alpha=0.91$ ), a 10-item questionnaire used to measure a global view of mHealth app usability, ${ }^{45,46}$ and the Mobile App Rating Scale (MARS; $\alpha=0.91) .{ }^{47}$

\section{Contextual Factors}

Known to contribute to hypertension self-management and health outcomes, contextual factors were assessed and included social support, spirituality, and depression. Perceived social support was measured on the 7-item Duke Subjective Social Support Index (DSSI; $\alpha=0.71$ ), for a total score of 14 , with higher scores indicating greater perceived social support. ${ }^{48}$ Spiritualty was measured on the 16-item Daily Spiritual Experience Scale 
(DSES) to assess an individual's perception of the transcendent in daily life. ${ }^{49}$ The DSES has demonstrated good reliability $(\alpha=0.90)$ in various patient populations, with lower scores representing a higher daily spiritual experience. ${ }^{49}$ Depression was measured with the 8-item PROMIS Emotional Distress Short Form, which has demonstrated adequate reliability. ${ }^{40}$ Scores on this scale range from 8 to 40 , with higher scores indicating higher levels of depression. ${ }^{40}$

\section{Analysis Plan}

Descriptive statistics were used to examine the distribution of study variables by group. Categorical variables were summarized using frequencies and percentages, while continuous variables were summarized by means and standard deviations. Groups were compared for equivalence in baseline characteristics after normality was verified using Chi-square for categorical data and independent twosample $t$-test or the Wilcoxon rank-sum test for continuous data. A paired $t$-test was used to examine group differences between study measures at baseline and 12 weeks.

To compare changes in systolic and diastolic BP, HRQoL, and scores on other study measures between the intervention and the control groups, a repeated measures linear model with first-order autoregressive covariance structure with SAS Proc Mixed was used to assess mean differences across three points over a 3-month period. Time (baseline, 8 weeks, and 12-week follow-up) served as the level of responses for the within-subjects factor, while the study group (intervention vs control) served as the between-subjects factor to examine the interaction of time $\mathrm{x}$ group. ${ }^{50}$ All statistical analysis was performed using SAS 14.1 software (Cary, NC), and p-values $<0.05$ were considered statistically significant.

\section{Results}

We enrolled 60 individuals; half were randomized to the intervention group (COACHMAN), and half were randomized to the EUC control group. The mean age of all participants was $59.48 \pm 8.89$ (range, $37-79$ years). The majority of the sample were women $(75 \%, n=45)$ and had approximately $14.61( \pm 3.34)$ years of education. About $68.3 \%$ of the participants were single and $48.3 \%$ reported being employed. Most of the sample had been diagnosed with hypertension for $17.35 \pm 9.73$ years, prescribed 1.90 ( \pm 0.95$)$ antihypertensive medications, and reported living with three or more chronic conditions. Table 2 summarizes the demographic characteristics of the sample stratified by study conditions. There were no significant differences in demographic characteristics between the control and intervention groups. The groups did not differ in terms of their clinical factors and hypertension-related characteristics (Table 3). No significant differences were found between the contextual factors-social support, spirituality, and depression between the intervention group and control group.

Table 4 shows the self-management process, health behaviors, and study outcomes for both study groups. After completing a 3-month technology-based intervention to improve hypertension self-management, the study participants in the intervention group did not show a statistically significant reduction in systolic and diastolic BP from baseline to 12 weeks when compared to the control group. However, the control group had a nonsignificant $2.17 \mathrm{mmHg}$ decrease in systolic BP. In terms of HRQoL, the groups did not differ in their mental and physical health at the end of 12 weeks. The intervention group showed a greater reduction in LDL cholesterol when compared to the control; however, this difference was not statistically significant $(P=0.065)$.

Table 4 shows a paired $t$-test analysis for study variables, outcomes, and clinical characteristics stratified by study groups. The mean medication-taking adherence score significantly improved in the intervention group between baseline and 3 months, $t(28)=2.41$ (95\% confidence interval [CI]: $0.09,2.36), P=0.023$ compared to those in the control group, $t(28)=1.85$ (95\% CI: $-0.158,3.05), P=0.075$. Sixty-two percent $(n=18)$ of the intervention group participants demonstrated $>80 \%$ use of the Medisafe app, responding to taking medication dose as prescribed.

Table 5 presents the unadjusted and adjusted repeated measures analyses of the intervention effects on systolic and diastolic BP, HRQoL, and medication adherence. Results showed that there were no statistically significant between-groups or within-groups effects for study outcomes-systolic and diastolic BP and HRQoL. However, there was a statistically significant within-groups effect for antihypertension medication adherence $(P=0.006)$, indicating the intervention had a moderate effect on increasing antihypertension medication-taking adherence.

\section{Discussion}

The purpose of this study was to examine the effectiveness of a community and technology-based approach to support self-management of hypertension and improve BP control in African Americans with hypertension. Study 
Table 2 Baseline Sociodemographic Variables of the Sample Stratified by Study Conditions

\begin{tabular}{|c|c|c|c|c|}
\hline Characteristics & Control Group $(n=30)$ & Intervention Group $(n=30)$ & $\chi^{2} / t$ & $p$ \\
\hline Age in years, mean $\pm S D$ ) & $58.97 \pm 8.37$ & $60.0 \pm 9.49$ & -0.45 & 0.656 \\
\hline Young (<49), n (\%) & $4(13.3)$ & $4(13.3)$ & 0.746 & 0.770 \\
\hline Middle (50-64), n (\%) & $18(60.0)$ & $15(50.0)$ & & \\
\hline Older (65 or above), n (\%) & $8(26.7)$ & II (36.7) & & \\
\hline Gender n (\%) & & & 2.22 & 0.136 \\
\hline Males & $5(16.67)$ & $10(33.33)$ & & \\
\hline Females & $25(83.3)$ & $20(66.7)$ & & \\
\hline Education in years, mean $\pm S D$ & $14.70 \pm 3.36$ & $14.52 \pm 3.38$ & 0.211 & 0.834 \\
\hline Marital Status, n (\%) & & & 6.653 & 0.248 \\
\hline Single & $22(73.33)$ & $19(63.33)$ & & \\
\hline Married & $8(26.7)$ & II (36.7) & & \\
\hline Employment & & & -0.766 & 0.45 \\
\hline Unemployed & $14(46.7)$ & $17(56.7)$ & & \\
\hline Employed & $16(53.3)$ & $13(43.3)$ & & \\
\hline Income & & & -0.562 & 0.576 \\
\hline$<\$ 20,000$ & $8(26.7)$ & $8(26.7)$ & & \\
\hline$\$ 20,000-\$ 59,999$ & II (36.7) & $9(30.0)$ & & \\
\hline$>\$ 60,000$ & II (36.7) & $13(43.3)$ & & \\
\hline
\end{tabular}

Notes: Values are expressed as either $\mathrm{n}(\%)$ or mean \pm SD. The P-value are for $\chi^{2}$ and independent two-sample $t$-test.

Table 3 Hypertension-Related Characteristics

\begin{tabular}{|c|c|c|c|c|}
\hline Characteristics & Control Group $(n=30)$ & Intervention Group $(n=30)$ & $\chi^{2} / t / W$ & $P$ value \\
\hline Years diagnosis with hypertension, mean \pm SD & $|5.7| \pm 10.34$ & $17.00 \pm 9.20$ & -0.512 & $0.6 \mathrm{II}$ \\
\hline No. of chronic diseases, mean \pm SD & $3.30 \pm 2.15$ & $3.93 \pm 2.03$ & -1.172 & 0.246 \\
\hline No. of BP medications prescribed, mean $\pm S D$ & $1.80 \pm 1.00$ & $2.00 \pm 0.91$ & -0.812 & 0.42 \\
\hline \multicolumn{5}{|l|}{ Class of BP Medications, $\mathrm{n}(\%)$} \\
\hline Diuretic treatment & $13(43.3)$ & $17(56.7)$ & 1.067 & 0.302 \\
\hline ACE inhibitor treatment & $7(23.3)$ & $7(23.3)$ & 0.00 & 1.00 \\
\hline Angiotensin receptor blocker treatment & II (36.7) & $7(23.3)$ & 1.270 & 0.26 \\
\hline Calcium channel blocker treatment & $10(33.3)$ & $15(50.0)$ & 1.74 & 0.19 \\
\hline Beta blocker treatment & $7(23.3)$ & $10(33.3)$ & 0.739 & 0.390 \\
\hline Smoker, n (\%) & $7(23.3)$ & $13(43.3)$ & 2.70 & 0.10 \\
\hline \multicolumn{5}{|l|}{$\mathrm{BP}$ at Screening visit, mean $\pm \mathrm{SD}$} \\
\hline Screening Systolic BP & $152.20 \pm 12.19$ & $156.67 \pm 90.53$ & -1.140 & 0.259 \\
\hline Screening Diastolic BP & $88.07 \pm 13.02$ & $90.53 \pm 14.66$ & -0.689 & 0.494 \\
\hline
\end{tabular}

Notes: Values are expressed as either $\mathrm{n}(\%)$ or mean $\pm \mathrm{SD}$. The P-value are for $\chi^{2}$ and independent two-sample $t$-test or Wilcoxon rank-sum test.

participants in the intervention group used three technology-based components-hypertension web-based education, a medication management app (Medisafe), and a home BP monitor, in addition to nurse counseling, to improve BP and medication adherence. Our results demonstrated that among African Americans with hypertension, the intervention did not significantly improve BP and HRQoL. Although our study hypothesis that individuals in the intervention group would have improved BP control and HRQoL compared to those in the control group was not supported, we found that individuals in the intervention group did significantly improve their antihypertensive medication-taking adherence over a 3-month period compared to the control group. Our findings are 
Table 4 Study Variables, Outcomes, and Clinical Characteristics Stratified by Study Condition

\begin{tabular}{|c|c|c|c|c|c|c|c|c|c|c|}
\hline \multirow[t]{3}{*}{ Variables } & \multicolumn{5}{|c|}{ Control Group $(n=30)$} & \multicolumn{5}{|c|}{ Intervention Group $(n=30)$} \\
\hline & \multicolumn{2}{|c|}{ Baseline } & \multicolumn{2}{|c|}{12 Weeks } & \multirow[t]{2}{*}{$P$ value } & \multicolumn{2}{|c|}{ Baseline } & \multicolumn{2}{|c|}{12 Weeks } & \multirow[t]{2}{*}{$P$ value } \\
\hline & Mean & SD & Mean & SD & & Mean & SD & Mean & SD & \\
\hline \multicolumn{11}{|l|}{ Health outcomes } \\
\hline Systolic BP, mmHg & 141.24 & 16.92 & 139.07 & 16.41 & 0.55 & $|38.5|$ & 14.77 & 139.06 & 16.54 & 0.87 \\
\hline Diastolic BP, mmHg & 85.28 & $|2.6|$ & 84.24 & 12.06 & 0.63 & 81.97 & 13.45 & 81.17 & 11.45 & 0.67 \\
\hline Physical health, HRQoL & 14.28 & 2.68 & 14.17 & 2.59 & 0.72 & 14.52 & 2.85 & $|4.4|$ & 3.01 & 0.76 \\
\hline Mental health, HRQoL & 13.38 & 2.46 & 13.72 & 3.39 & 0.26 & 13.83 & 2.83 & 13.83 & 3.13 & 1.00 \\
\hline \multicolumn{11}{|l|}{ Clinical characteristics } \\
\hline Pulse & 70.96 & 11.54 & 72.71 & 12.40 & 0.43 & 68.13 & 13.79 & 73.17 & 12.39 & 0.009 \\
\hline Weight, lbs & 217.73 & 47.84 & 220.21 & 49.26 & 0.003 & 210.15 & 52.27 & 211.30 & 53.12 & 0.259 \\
\hline Body mass index, $\mathrm{kg} / \mathrm{m} 2$ & 35.16 & 7.60 & 35.53 & 7.84 & 0.005 & 35.03 & 8.07 & 34.73 & 8.31 & 0.578 \\
\hline HDL cholesterol, mg/dL & 51.75 & 12.09 & 52.78 & 12.53 & 0.45 & 53.39 & 15.09 & 51.36 & 15.48 & 0.060 \\
\hline LDL cholesterol, mg/dL & 111.96 & 32.66 & 107.54 & 36.19 & 0.43 & 113.08 & 35.85 & 105.00 & 29.35 & 0.061 \\
\hline \multicolumn{11}{|l|}{ Behavioral outcomes } \\
\hline Medication adherence & 13.38 & 6.09 & 11.93 & 4.43 & 0.075 & 12.00 & 3.43 & 10.72 & 2.20 & 0.023 \\
\hline \multicolumn{11}{|l|}{ Self-management process } \\
\hline Hypertension knowledge & 17.93 & 3.05 & 18.72 & 2.27 & 0.14 & 19.07 & 1.69 & 19.38 & 1.25 & 0.38 \\
\hline Self-efficacy & 41.65 & 15.24 & 45.48 & 13.92 & 0.09 & 46.34 & 11.24 & 46.62 & 10.07 & 0.88 \\
\hline \multicolumn{11}{|l|}{ Contextual factors } \\
\hline Social support & 11.90 & 2.57 & 11.79 & 2.47 & 0.80 & 12.34 & 2.00 & 12.03 & 2.47 & 0.37 \\
\hline Spirituality & 33.03 & 10.64 & 31.21 & 9.69 & 0.53 & 32.00 & 14.06 & 33.69 & 14.52 & 0.23 \\
\hline Depression & 12.45 & 4.47 & 12.17 & 4.61 & 0.61 & 13.03 & 5.78 & 13.63 & 5.26 & 0.17 \\
\hline
\end{tabular}

Note: P-values from paired $t$-test.

Abbreviations: BP, blood pressure; HRQoL, health-related quality of life.

Table 5 Unadjusted and Adjusted Model of Repeated Measures for Within- and Between-Group Effects of Study Outcomes

\begin{tabular}{|c|c|c|c|c|c|c|c|}
\hline \multirow[t]{2}{*}{ Variables } & & \multicolumn{3}{|c|}{ Unadjusted Model } & \multicolumn{3}{|c|}{ Adjusted Model $^{\mathrm{a}}$} \\
\hline & & $d f$ & $\boldsymbol{F}$ & $P$ & $d f$ & $\boldsymbol{F}$ & $P$ \\
\hline \multirow[t]{3}{*}{ Systolic BP } & Time & 2 & 0.03 & 0.9659 & 2 & 0.04 & 0.9639 \\
\hline & Study group & 1 & 0.15 & 0.7036 & I & 0.03 & 0.8661 \\
\hline & Interaction $^{\mathrm{b}}$ & 2 & 0.12 & 0.8911 & 2 & 0.12 & 0.8903 \\
\hline \multirow[t]{3}{*}{ Diastolic BP } & Time & 2 & 0.19 & 0.8305 & 2 & 0.19 & 0.8260 \\
\hline & Study group & 1 & 1.84 & 0.1800 & I & 1.10 & 0.2979 \\
\hline & Interaction ${ }^{\mathrm{b}}$ & 2 & 0.41 & 0.6650 & 2 & 0.40 & 0.6708 \\
\hline \multirow[t]{3}{*}{ Physical health, HRQoL } & Time & 1 & 0.22 & 0.6392 & I & 0.21 & 0.6475 \\
\hline & Study group & 1 & 0.09 & 0.7643 & I & 0.09 & 0.7606 \\
\hline & Interaction $^{\mathrm{b}}$ & 1 & 0.00 & 0.9860 & I & 0.00 & 0.9867 \\
\hline \multirow[t]{3}{*}{ Mental health, HRQoL } & Time & 1 & 0.76 & 0.3862 & 1 & 0.78 & 0.3807 \\
\hline & Study group & 1 & 0.10 & 0.7542 & I & 0.04 & 0.8513 \\
\hline & Interaction $^{\mathrm{b}}$ & 1 & 0.65 & 0.4227 & 1 & 0.66 & 0.4214 \\
\hline \multirow[t]{3}{*}{ Medication adherence } & Time & 2 & 4.52 & $0.0130 *$ & 2 & 4.51 & $0.0131 *$ \\
\hline & Study group & 1 & 1.80 & 0.1848 & I & 1.37 & 0.2461 \\
\hline & Interaction ${ }^{\mathrm{b}}$ & 2 & 0.04 & 0.9564 & 2 & 0.05 & 0.9557 \\
\hline
\end{tabular}

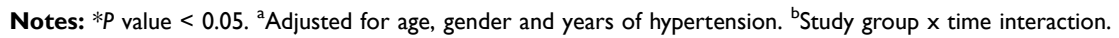

Abbreviations: BP, blood pressure; HRQoL, health-related quality of life. 
similar to studies aiming to improve BP control and medication adherence using mHealth and/or related technology. ${ }^{51,52}$

In terms of achieving lower BP targets (BP $<130 / 80$ $\mathrm{mmHg}$ ) in at least $65 \%$ of those individuals assigned to the intervention group, only $22 \%$ of that group had their systolic BP controlled ( $<130 \mathrm{mmHg}$ ) compared to $21 \%$ of the control group, while diastolic BP was slightly above the recommended $<80 \mathrm{mmHg}$ in both groups. However, it is important to point out that $60 \%$ of the intervention group exhibited average systolic/diastolic BP reductions of $11.2 \mathrm{mmHg}$ and $8.5 \mathrm{mmHg}$, respectively, over a 3-month period, indicating a clinically meaningful decrease in BP. Similarly, 52\% of the control group exhibited an average systolic/diastolic BP reduction of 14.79 $\mathrm{mmHg}$ and $9.33 \mathrm{mmHg}$, respectively, over 12 weeks. One plausible explanation for the lack of significant differences between groups in terms of BP reduction could be partly explained by all study participants receiving a study provided home BP monitoring device that possibly increased their self-monitoring of BP. From a clinical perspective, research suggests that $\mathrm{a} \geq 10 \mathrm{mmHg}$ reduction in systolic $\mathrm{BP}$ is likely to reduce the incidents of stroke by $37 \%$, coronary heart disease by $21 \%$, and mortality from CVD by $25 \% .^{2,53}$ Study findings also suggested that using technology to support self-managing hypertension is acceptable by African Americans with hypertension as two-thirds of the intervention group had $80 \%$ or greater response rate to all components, with a $90 \%$ retention rate.

Regarding clinical characteristics, paired t-tests showed a slight reduction in LDL cholesterol in both groups, with the intervention group demonstrating a nonsignificant $8.08 \mathrm{mg} / \mathrm{dL}$ point reduction compared to $4.41 \mathrm{mg} / \mathrm{dL}$ reduction in the control group. Epidemiological studies suggest that elevated LDL cholesterol $(>100 \mathrm{mg} / \mathrm{dL})$ is a major risk factor for atherosclerotic cardiovascular disease, and a small reduction in LDL cholesterol would reduce that risk. ${ }^{54}$ For instance, for every $1 \mathrm{mg} / \mathrm{dL}(0.03$ $\mathrm{mmol} / \mathrm{L}$ ) reduction in LDL cholesterol levels, total mortality is reduced by approximately $12 \%$, and major vascular events are reduced by $21 \%$. $^{54,55}$

Furthermore, considering the underpinnings of the theoretical framework guiding this study, ${ }^{27}$ the IFSMT model postulates that individuals who engage in self-management behaviors improve their health outcomes through the selfmanagement process. The self-management mechanisms by which behavioral change is influenced have been extensively explored, ${ }^{27}$ and it is through this process that knowledge and self-regulation enhance health behavior change and improves HRQoL. In this study, we explored hypertension knowledge and self-efficacy for managing a chronic condition. At baseline, we observed that both groups had moderately high levels of hypertension knowledge at baseline and 12 weeks. One explanation could be related to the fact that the participants in this study, on average, had been diagnosed and living with hypertension for approximately 16 years.

In terms of self-efficacy, both groups self-reported fair to good scores on the self-efficacy measure in terms of managing their hypertension. The intervention group reported slightly higher levels of self-efficacy from baseline to 12 weeks when compared to the control. Self-efficacy has been regarded as a significant component in adherence to managing hypertension and is associated with improving self-management activities such as medication-taking, healthy eating, and physical activity. $^{56}$ In our study, participants rated their selfefficacy somewhat fair (42 out of 60 total points), which is consistent with other studies. ${ }^{56,57}$ Hypertension self-management encompasses a broad array of behaviors, ${ }^{58}$ and our findings suggest that African Americans could benefit from interventions that specifically target and strengthen one's self-efficacy beyond adherence to antihypertensive medicationtaking. ${ }^{56,59}$ Despite fair self-efficacy scores, our findings demonstrated a moderate significant within-group effect for antihypertensive medication-taking adherence over a 3-month period in the intervention group. However, our findings did not reflect significant between- and within-group effects or time-by-group interaction effects for all study outcome variables. Additionally, social support, spirituality, and depression did not differ between the groups.

Control of hypertension in African Americans poses a distinct clinical challenge, as aggressive treatment is required to achieve an optimal and lower BP target. ${ }^{1,60}$ Research suggests that treating systolic BP to achieve $<130 \mathrm{mmHg}$ in African Americans to improve overall $\mathrm{BP}$ and reduce mortality may require up to three antihypertensive medications. ${ }^{1,60}$ For example, at study entry, approximately half of the sample was prescribed on average 1.9 antihypertensive medications, with $50 \%$ prescribed a thiazide diuretic and/or $42 \%$ were prescribed a calcium channel blocker. Compelling evidence in randomized controlled trials has demonstrated that thiazide diuretics and calcium channel blockers are superior to renin-angiotensin 
inhibitors, alpha blockers, and beta blockers in lowering $\mathrm{BP}$ in the African American population. ${ }^{1}$

Despite the evidence for BP treatment, ${ }^{1}$ our study findings of a lack of achieved BP control may be due to clinical inertia (failure to adequately prescribe antihypertensives), ${ }^{61}$ blunted by patients achieving a previously recommended BP target of $<140 / 90 \mathrm{mmHg}$ vs the current target of $<130 / 80 \mathrm{mmHg}$. In fact, at the beginning of this study, as the US hypertension guideline emerged, organizations such as the American College of Physicians and the American Academy of Family Physicians denounced the lower BP thresholds complicating providers' decisions to shift practice to intensify BP treatment to the lower BP threshold. ${ }^{62,63}$ Moreover, our study collected information about prescribed antihypertensive medications only at baseline. Given the patientcentered focused of this pilot study, we did not take into account whether or not participants' followed up with their health care provider as recommended during nurse counseling sessions, or if participants' antihypertensive medications were intensified over a 3-month period. Therefore, future research should consider a medication protocol that emphasizes effective multidrug regimens in African Americans consistent with current recommendations prior to determining the effectiveness of a behavioral intervention using a technology-based intervention.

\section{Strengths and Limitations}

Research recommends lowering BP targets to $<130$ $\mathrm{mmHg},{ }^{1}$ which requires aggressive treatment strategies that can make controlling BP a challenge. Technologybased interventions, including mHealth technology, have demonstrated improvement in the self-management of chronic conditions, ${ }^{14,15}$ but often lack a theoretical framework and diverse participants, especially underserved African Americans with hypertension. A strength of this study is that this is the first theory-based study evaluating the effects of technology-based intervention in African Americans guided by the IFSMT framework, uniquely combined contextual factors and the self-management process to engage individuals in health behaviors to improve BP control. An important finding from this study is that self-report of adherence to antihypertensive medicationtaking improved in the intervention group, despite the lack of corresponding reductions in systolic and diastolic BP. Taking these findings into account, self-management interventions that use technology alone will be insufficient to support or sustain self-managing hypertension in
African Americans without an effective treatment regimen prescribed to lower their BP. ${ }^{1}$

This study is not without limitations. First, it is possible that the small convenience sample, a lack of heterogeneity in terms of sociodemographic characteristics (eg gender), and the brevity of the 12-week timeframe, limited our ability to observe the full benefits of the intervention in this pilot study. Second, participants in this study had more than one chronic condition, including living with hypertension for 2-3 decades, which might require a longer intervention period, as well as a planned maintenance phase. Another possible limitation was of this study was that all participants received a study-provided BP monitor, which could have increased self-monitoring of their BP, and/or the Hawthorne effect in the control group that may have contributed to the lack of statistically significant differences in the outcomes between the two study groups.

\section{Conclusion}

In summary, technology, including mHealth, is increasingly being used to improve chronic disease management and health outcomes. Our findings suggest that behavioral interventions using technology can improve adherence to medication-taking. However, technology alone may be insufficient to support and sustain self-managing hypertension without the appropriate medication treatment being prescribed. Further research is warranted in a larger sample and should include the standardization of medication management to isolate the effects of technology-based behavioral interventions on changes in BP.

\section{Data Sharing Statement}

The Authors agree to make data and materials supporting the results or analyses presented in their paper available from CHS upon reasonable request.

\section{Acknowledgments}

This study was support by the National Institute on Minority Health and Health Disparities (5U54MD002265-12) and the University Hospitals Cleveland Medical Center and the Clinical and Translational Science Collaborative of Cleveland, 4UL1TR000439 from the National Center for Advancing Translational Sciences (NCATS) component of the National Institutes of Health and NIH roadmap for Medical Research. We gratefully acknowledge our community partners (American Heart Association 
Multicultural Initiative Leader, Cleveland Council of Black Nurses, and the Cleveland Office of Minority Health) and our research staff for their involvement in the research process and conduct of this study.

\section{Author Contributions}

All authors made a significant contribution to the work reported, whether that is in the conception, study design, execution, acquisition of data, analysis and interpretation, or in all these areas; took part in drafting, revising or critically reviewing the article; gave final approval of the version to be published; have agreed on the journal to which the article has been submitted; and agree to be accountable for all aspects of the work.

\section{Disclosure}

The authors have no conflicts of interest, including no relevant financial or non-financial in the subject or materials discussed in this paper. The preliminary findings of this study were presented at the 2019 Gerontological Society of America's 71st Annual Scientific conference as part of a symposium. The presentation's abstract was published in Innovative Aging. https://doi.org/10.1093/geroni/igz038. $\underline{269}$

\section{References}

1. Whelton PK, Carey RM, Aronow SW, et al. 2017 ACC/AHA/AAPA/ $\mathrm{ABC} / \mathrm{ACPM} / \mathrm{AGS} / \mathrm{APhA} / \mathrm{ASH} / \mathrm{ASPC} / \mathrm{NMA} / \mathrm{PCNA}$ Guideline for the prevention, detection, evaluation, and management of high blood pressure in adults a report of the American College of Cardiology/ American Heart Association Task Force on Clinical Practice Guidelines. Hypertension. 2017:HYP.0000000000000065. doi:10.1161/HYP.0000000000000065

2. Center for Disease Control and Prevention (CDC). Facts About Hypertension. 2020. Available from: https://www.cdc.gov/bloodpres sure/facts.htm. Accessed July 10, 2020.

3. Gu Q, Burt VL, Dillon CF, Yoon S. Trends in antihypertensive medication use and blood pressure control among United States adults with hypertension: the national health and nutrition examination survey, 2001 to 2010. Circulation. 2012;126(17):2105-2114. doi:10.1161/ circulationaha.112.096156

4. Benjamin EJ, Muntner P, Alonso A, et al. Heart disease and stroke statistics-2019 update: a report from the American Heart Association. Circulation. 2019;139(10):e56-e528. doi:10.1161/cir.000000000 0000659

5. Center for Disease Control and Prevention (CDC). Racial/ethnic disparities in the awareness, treatment, and control of hypertension United States, 2003-2010. MMWR Morb Mortal Wkly Rep. 2013;62 (18):351-355.

6. Whelton P, Einhorn PT, Muntner P, et al.; for the National Heart Lung and Blood Institute Working Group. Working group on research needs to improve hypertension treatment and control in African Americans. Research needs to improve hypertension treatment and control in African Americans. Hypertension. 2016;68:1066-1072. doi:10.1161/ HYPERTENSIONAHA.116.07905
7. Abegaz TM, Shehab A, Gebreyohannes EA, Bhagavathula AS, Elnour AA. Nonadherence to antihypertensive drugs: a systematic review and meta-analysis. Medicine. 2017;96(4):e5641. doi:10.1097/ md.0000000000005641

8. Vrijens B, Antoniou S, Burnier M, de la Sierra A, Volpe M. Current situation of medication adherence in hypertension. Front Pharmacol. 2017;8:100. doi:10.3389/fphar.2017.00100

9. Lewis LM, Ogedegbe C, Ogedegbe G. Enhancing adherence of antihypertensive regimens in hypertensive African-Americans: current and future prospects. Expert Rev Cardiovasc Ther. 2012;10 (11):1375-1380. doi:10.1586/erc.12.138

10. Burnier M, Egan BM. Adherence in hypertension. Circ Res. 2019;124(7):1124-1140. doi:10.1161/CIRCRESAHA.118.313220

11. Carnethon MR, Pu J, Howard G, et al. Cardiovascular health in African Americans: a scientific statement from the American Heart Association. Circulation. 2017;136(21):e393-e423. doi:10.1161/ cir.0000000000000534

12. Glynn LG, Murphy AW, Smith SM, Schroeder K, Fahey T. Interventions used to improve control of blood pressure in patients with hypertension. Cochrane Database Syst Rev. 2010;3:Cd005182. doi:10.1002/14651858.CD005182.pub4

13. Ferdinand KC, Yadav K, Nasser SA, et al. Disparities in hypertension and cardiovascular disease in blacks: the critical role of medication adherence. J Clin Hypertens. 2017;19(10):1015-1024. doi:10.1111/ jch.13089

14. Burke LE, Ma J, Azar KM, et al. Current science on consumer use of mobile health for cardiovascular disease prevention: a scientific statement from the American Heart Association. Circulation. 2015;132 (12):1157-1213. doi:10.1161/cir.0000000000000232

15. Chen S, Gong E, Kazi DS, et al. Using mobile health intervention to improve secondary prevention of coronary heart diseases in China: mixed-methods feasibility study. JMIR Mhealth Uhealth. 2018;6(1): e9. doi:10.2196/mhealth.7849

16. Hamine S, Gerth-Guyette E, Faulx D, Green BB, Ginsburg AS. Impact of mHealth chronic disease management on treatment adherence and patient outcomes: a systematic review. $J$ Med Internet Res. 2015;17(2):e52. doi:10.2196/jmir.3951

17. Schober DJ, Tate M, Rodriguez D, Ruppar TM, Williams J, Lynch E. High blood pressure medication adherence among urban, African Americans in the Midwest United States. J Racial Ethn Health Disparities. 2020. doi:10.1007/s40615-020-00819-2

18. Abdullah A, Liew SM, Hanafi NS, et al. What influences patients' acceptance of a blood pressure telemonitoring service in primary care? A qualitative study. Patient Prefer Adherence. 2016;10:99-106. doi:10.2147/ppa.s94687

19. Band R, Bradbury K, Morton K, et al. Intervention planning for a digital intervention for self-management of hypertension: a theory-, evidence- and person-based approach. Implement Sci. 2017;12(1):25. doi:10.1186/s13012-017-0553-4

20. Bobrow K, Farmer AJ, Springer D, et al. Mobile phone text messages to support treatment adherence in adults with high blood pressure (SMS-Text Adherence Support [StAR]): a single-blind, randomized trial. Circulation. 2016;133(6):592-600. doi:10.1161/circulationaha.115.017530

21. Davidson TM, McGillicuddy J, Mueller M, et al. Evaluation of an mHealth medication regimen self-management program for African American and hispanic uncontrolled hypertensives. J Pers Med. 2015;5(4):389-405. doi:10.3390/jpm5040389

22. Smith A. African Americans and technology use: a demographic portrait pew research center, internet and technology. Available from: http://www.pewinternet.org/2014/01/06/african-americans-andtechnology-use/. Accessed June 20, 2020.

23. Nielsen. Multifaceted connections: African-American media usage outpaces across platform. 2015. Available from: https://www.niel sen.com/us/en/insights/article/2015/multifaceted-connections-africanamerican-media-usage-outpaces-across-platforms/. Accessed May 20, 2020. 
24. Doshi R, Aseltine RH, Sabina AB, Graham GN. Interventions to improve management of chronic conditions among racial and ethnic minorities. J Racial Ethn Health Disparities. 2017;4(6):1033-1041. doi:10.1007/s40615-017-0431-4

25. Still CH, Dang PB, Malaker D, Peavy TD. The design and rationale of a pilot study: a community and tech-based approach for hypertension self-management (coachman). J Natl Black Nurses Assoc. 2020;31(1):52-59.

26. Park LG, Beatty A, Stafford Z, Whooley MA. Mobile phone interventions for the secondary prevention of cardiovascular disease. Prog Cardiovasc Dis. 2016;58(6):639-650. doi:10.1016/j.pcad.201 6.03.002

27. Ryan P, Sawin KJ. The individual and family self-management theory: background and perspectives on context, process, and outcomes. Nurs Outlook. 2009;57(4):217-225. doi:10.1016/j.outlook.2008.10.004

28. Ryan P, Papanek P, Csuka ME, et al. Background and method of the striving to be strong study a RCT testing the efficacy of a m-health self-management intervention. Contemp Clin Trials. 2018;71:80-87. doi:10.1016/j.cct.2018.06.006

29. Kumah-Crystal YA, Hood KK, Ho YX, et al. Technology use for diabetes problem solving in adolescents with type 1 diabetes: relationship to glycemic control. Diabetes Technol Ther. 2015;17 (7):449-454. doi:10.1089/dia.2014.0422

30. Kingry C, Bastien A, Booth G, et al. Recruitment strategies in the Action to Control Cardiovascular Risk in Diabetes (ACCORD) trial. Am J Cardiol. 2007;99(12a):68i-79i. doi:10.1016/j.amjcard.20 07.03 .025

31. Pressel S, Davis BR, Louis GT, et al. Participant recruitment in the Antihypertensive and Lipid-Lowering Treatment to Prevent Heart Attack Trial (ALLHAT). Control Clin Trials. 2001;22(6):674-686. doi:10.1016/s0197-2456(01)00177-5

32. Ramsey TM, Snyder JK, Lovato LC, et al. Recruitment strategies and challenges in a large intervention trial: systolic blood pressure intervention trial. Clin Trials. 2017;13(Generic):319-330. doi:10.1177/ 1740774516631735

33. Whitehead AL, Julious SA, Cooper CL, Campbell MJ. Estimating the sample size for a pilot randomised trial to minimise the overall trial sample size for the external pilot and main trial for a continuous outcome variable. Stat Methods Med Res. 2016;25(3):1057-1073. doi:10.1177/0962280215588241

34. Ferdinand KC, Patterson KP, Taylor C, Fergus IV, Nasser SA, Ferdinand DP. Community-based approaches to prevention and management of hypertension and cardiovascular disease. J Clin Hypertens. 2012;14(5):336-343. doi:10.1111/j.1751-7176.201 2.00622.x

35. Hurtado M, Spinner JR, Yang M, et al. Knowledge and behavioral effects in cardiovascular health: community health worker health disparities initiative, 2007-2010. Prev Chronic Dis. 2014;11:E22. doi: $10.5888 /$ pcd 11.130250

36. Kim S, Koniak-Griffin D, Flaskerud JH, Guarnero PA. The impact of lay health advisors on cardiovascular health promotion: using a community-based participatory approach. $J$ Cardiovasc Nurs. 2004;19(3):192-199. doi:10.1097/00005082-200405000-00008

37. Institute of Medicine (IOM). Exploring Challenges, Progress, and New Models for Engaging the Public in the Clinical Research Enterprise: Clinical Research Roundtable Workshop Summary. Washington, DC: The National Academies Press; 2003.

38. Muntner P, Shimbo D, Carey RM, et al. Measurement of blood pressure in humans: a scientific statement from the American Heart Association. Hypertension. 2019;73(5):e35-e66. doi:10.1161/ HYP.0000000000000087

39. Hays RD, Bjorner JB, Revicki DA, Spritzer KL, Cella D. Development of physical and mental health summary scores from the patient-reported outcomes measurement information system (PROMIS) global items. Qual Life Res. 2009;18(7):873-880. doi:10.1007/s11136-009-9496-9
40. Cella D, Riley W, Stone A, et al. The Patient-Reported Outcomes Measurement Information System (PROMIS) developed and tested its first wave of adult self-reported health outcome item banks: 2005-2008. J Clin Epidemiol. 2010;63(11):1179-1194. doi:10.1016/ j.jclinepi.2010.04.011

41. Culig J, Leppee M. From morisky to hill-bone: self-reports scales for measuring adherence to medication. Coll Antropol. 2014;38 (1):55-62

42. Kim MT, Hill MN, Bone LR, Levine DM. Development and testing of the hill-bone compliance to high blood pressure therapy scale. Prog Cardiovasc Nurs. 2000;15(3):90-96. doi:10.1111/j.17517117.2000.tb00211.x

43. Erkoc SB, Isikli B, Metintas S, Kalyoncu C. Hypertension Knowledge-Level Scale (HK-LS): a study on development, validity and reliability. Int $J$ Environ Res Public Health. 2012;9 (3):1018-1029. doi:10.3390/ijerph9031018

44. Lorig KR, Sobel DS, Ritter PL, Laurent D, Hobbs M. Effect of a self-management program on patients with chronic disease. Eff Clin Pract. 2001;4(6):256-262.

45. Brooke J. System Usability Scale(SUS): a quick and dirty scale. In: Jordan PW, Weerdmester BA, MeClelland AL, editors. London: Taylor and Francis; 1996. Chapter 21, page 6.

46. Bangor A, Kortum PT, Miller JT. An empirical evaluation of the system usability scale. Int J Hum Comput Interact. 2008;24 (6):574-594. doi:10.1080/10447310802205776

47. Domnich A, Arata L, Amicizia D, et al. Development and validation of the Italian version of the mobile application rating scale and its generalisability to apps targeting primary prevention. BMC Med Inform Decis Mak. 2016;16:83. doi:10.1186/s12911-016-0323-2

48. Koenig HG, Westlund RE, George LK, et al. Abbreviating the duke social support index for use in chronically ill elderly individuals. Psychosomatics. 1993;34(1):61-69. doi:10.1016/S0033-3182(93) 71928-3

49. Underwood LG, Teresi JA. The daily spiritual experience scale: development, theoretical description, reliability, exploratory factor analysis, and preliminary construct validity using health related data. Ann Behav Med. 2002;24(1):22-33. doi:10.1207/ S15324796ABM2401 04

50. Field A. Discovering Statistics Using SPSS. 3rd ed. London: SAGE Publications; 2009.

51. Buis L, Hirzel L, Dawood RM, et al. Text messaging to improve hypertension medication adherence in African Americans from primary care and emergency department settings: results from two randomized feasibility studies. JMIR Mhealth Uhealth. 2017;5(2): e9. doi: $10.2196 /$ mhealth. 6630

52. Morawski K, Ghazinouri R, Krumme A, et al. Association of a smartphone application with medication adherence and blood pressure control: the MedISAFE-BP randomized clinical trial. JAMA Intern Med. 2018;178(6):802-809. doi:10.1001/jamainternmed.2 018.0447

53. Carey RM, Muntner P, Bosworth HB, Whelton PK. Prevention and control of hypertension: JACC health promotion series. $\mathrm{J}$ Am Coll Cardiol. 2018;72(11):1278-1293. doi:10.1016/j.jacc.2018.07.008

54. Arnett DK, Blumenthal RS, Albert MA, et al. 2019 ACC/AHA Guideline on the primary prevention of cardiovascular disease: executive summary: a report of the American College of Cardiology/American Heart Association Task Force on Clinical Practice Guidelines. J Am Coll Cardiol. 2019;74(10):1376-1414. doi:10.1016/j.jacc.2019.03.009

55. Soran H, Dent R, Durrington P. Evidence-based goals in LDL-C reduction. Clin Res Cardiol. 2017;106(4):237-248. doi:10.1007/ s00392-016-1069-7

56. Warren-Findlow J, Seymour RB, Brunner Huber LR. The association between self-efficacy and hypertension self-care activities among African American adults. J Community Health. 2012;37(1):15-24. doi:10.1007/s10900-011-9410-6 
57. Ellis JL, Kovach CR, Fendrich M, et al. Factors related to medication self-management in African American older women. Res Gerontol Nurs. 2019;12(2):71-79. doi:10.3928/19404921-20190206-01

58. Ogedegbe G. Barriers to optimal hypertension control. J Clin Hypertens. 2008;10(8):644-646. doi:10.1111/j.1751-7176.2008.0 8329.x

59. MJ RS L, Jia H, Velozo CA, Gruber-Baldini AL, Shulman LM. Selfefficacy for managing hypertension and comorbid conditions. World J Hypertens. 2019;9(3):30-41. doi:10.5494/wjh.v9.i3.30

60. Still CH, Rodriguez CJ, Wright JT Jr, et al. Clinical outcomes by race and ethnicity in the Systolic Blood Pressure InterventionTrial (SPRINT). Am J Hypertens. 2017;hpx138:1-11. doi:10.1093/ajh/ hpx 138
61. Milman T, Joundi RA, Alotaibi NM, Saposnik G. Clinical inertia in the pharmacological management of hypertension: a systematic review and meta-analysis. Medicine. 2018;97(25):e11121. doi:10.1097/md.0000000000011121

62. Bakris G, Sorrentino M. Redefining hypertension - assessing the new blood-pressure guidelines. $N$ Engl J Med. 2018;378(6):497-499. doi:10.1056/NEJMp1716193

63. Qaseem A, Wilt TJ, Rich R, et al. Pharmacologic treatment of hypertension in adults aged 60 years or older to higher versus lower blood pressure targets: a clinical practice guideline From the American college of physicians and the American academy of family physicians. Ann Intern Med. 2017;166(6):430-437. doi:10.7326/M16-1785

\section{Publish your work in this journal}

Patient Preference and Adherence is an international, peer-reviewed, open access journal that focusing on the growing importance of patient preference and adherence throughout the therapeutic continuum. Patient satisfaction, acceptability, quality of life, compliance, persistence and their role in developing new therapeutic modalities and compounds to optimize clinical outcomes for existing disease states are major areas of interest for the journal. This journal has been accepted for indexing on PubMed Central. The manuscript management system is completely online and includes a very quick and fair peer-review system, which is all easy to use. Visit http:// www.dovepress.com/testimonials.php to read real quotes from published authors. 